\title{
CoB Ön Alaşımlarının Alüminotermik Redüksiyon Yöntemiyle Üretilmesi ve Termokimyasal Modellenmesi
}

\author{
Ahmet TURAN*, Mehmet BUĞDAYCI \\ Kimya ve Süreç Mühendisliği Bölümü, Mühendislik Fakültesi, Yalova Üniversitesi, 77200, Yalova, Türkiye \\ *aturan@yalova.edu.tr
}

Received/Geliș: 28.11.2019

Accepted/Kabul: 13.02 .2020

\begin{abstract}
Öz: $\mathrm{Bu}$ çalışmada $\mathrm{CoB}$ ön alaşımlarının metalotermik (alüminotermik) redüksiyon yöntemi ile üretim parametrelerinin belirlenmesi üzerine çalışılmıştır. Çalışmada redüktan olarak aluminyum kullanılmış ve redüktan stokiyometrisindeki değişimin ürünler üzerindeki etkisi incelenmiş̧ir. Redüksiyon sistemi FactSage 7.1 programıla termokimyasal olarak modellenmiş, deneysel sonuçlar ile tutarlı bulgulara ulaşılmıştır. Deneysel çalışmalar sonunda elde edilen ürünler, X-1şılları difraksiyon spektrometrisi (XRD), optik mikroskobi, taramalı elektron mikroskobisi (SEM-EDS) ve mikro-vickers sertlik ölçüm yöntemleri ile karakterize edilmiştir. Karakterizasyon sonuçları incelendiğinde metal oluşum miktarının artan aluminyum stokiyometrisi ile yükseldiği gözlenirken, hedef alaşıma en yakın kompozisyonun $\mathrm{Al}$ stokiyometrisinin en düşük olduğu \%100'lük oranda elde edildiği görülmüştür. Ürünlerin sertlik değişimi incelendiğinde, hedef alaşıma en yakın kompozisyonda olan \%100 stokiyometrik aluminyum içeren deneyde $950 \mathrm{HV} 1$ 'lik değer ile en yüksek sertliğe ulaşıldığı belirlenmiş, yapıya giren Co-Al fazının alaşımın sertlik değerini olumsuz etkilediği görülmüştür. Optik mikroskop incelemeleri sonucunda açık ve koyu renkten oluşan iki faz görülmüş, koyu renkli fazın Co-Al bileşiminden oluşan yapı olduğu sonucuna varılmışıı. Artan Al miktarıyla koyu renkli bu fazın miktarının da arttığ1 görülmüş, gerek kompozisyondaki farklılıkların, gerekse sertlikteki düşüşlerin bu sebeple oluştuğu düşünülmektedir. Termokimyasal incelemeler ve deneysel çalı̧̧malar sonucunda bu alaşımın alüminotermik redüksiyon ile üretilebileceği ve yapılabilecek ilaveler ile istenilen kompozisyonda alaşım üretiminin mümkün olabileceği sonucuna varılmıştır. Gerçekleştirilen literatür taramasında $\mathrm{CoB}$ alaşımlarının alüminotermik olarak üretimine ilişkin çalışma bulunmamış ve bu çalışmanın ilgili ön alaşımın metalotermik üretimi üzerine gelecek çalışmalara yön gösterici olacağı kanaati oluşmuştur.
\end{abstract}

Anahtar kelimeler: CoB, Metalotermik Redüksiyon, Pirometalurji.

\section{Production and Thermochemical Modelling of CoB Pre-Alloys through Aluminothermic Reduction Method}

\footnotetext{
Abstract: In the present study, experiments were carried out to determine the production parameters of CoB prealloys through metallothermic (aluminothermic) reduction method. The aluminium was used as reductant in this study and, effects of Al stoichiometry on product properties were investigated. Reduction system was modelled by using FactSage 7.1 thermochemical simulation program and, results were consistent with experimental results. Experimental products were characterized by means of X-rays diffraction spectrometry (XRD), optical microscopy, scanning electron microscopy (SEM-EDS) and micro-vickers hardness testing methods. When characterization results were investigated, it was understood that the amount of reduced metal increased with the increase in aluminium stoichiometry whilst the closest composition to the target alloy was obtained in the experiment with the lowest $\mathrm{Al}$ stoichiometry as $100 \%$. In hardness results, the highest value was measured as $950 \mathrm{HV} 1$ for the sample produced with $100 \% \mathrm{Al}$ stoichiometry. On the other hand, the increase in $\mathrm{Al}$ stoichiometry caused the increase in $\mathrm{CoAl}$ formation in microstructures and, therefore hardness values decreased. In optical microscopy micrographs, two phases, dark and bright, were observed in microstructures and, it was anticipated that dark phases were CoAl. The ratio of dark $\mathrm{CoAl}$ phase increased with the increase in aluminium stoichiometry and, it was predicted that it was the reason of either composition change and fall in hardness values. As a result of thermochemical investigations and experiments, it was thought that the alloy can Bu makaleye atıf yapmak için

Turan, A., Buğdaycl, M., “CoB Ön Alaşımlarının Alüminotermik Redüksiyon Yöntemiyle Üretilmesi ve Termokimyasal Modellenmesi” El-Cezerî Fen ve Mühendislik Dergisi 2020, 7 (2); 436-447. 
be produced by using aluminothermic reduction method and, it is possible to produce almost pure samples with some basic modifications. There are no accounts in the literature on the aluminothermic reduction of CoB prealloys and, it was predicted that the present study will help further studies in this area.

Keywords: CoB, Metallothermic Reduction, Pyrometallurgy

\section{Giriş}

Kobalt bor ön alaşımları elektrik/elektronik sanayiinde, trafo saçlarının imalinde kullanılmaktadır. $\mathrm{Bu}$ ön alaşımlar yarı iletken, lehim, sızdırmazlık malzemesi, tıraş bıçağı ve refrakter malzeme üretiminde de kullanım alanı bulmaktadır [1,2]. Amorf alaşımların manyetik özelliklerinin keşfi ile bu alaşımların elektrik/elektronik sanayiinde kullanılabilmesi için araştırmalar başlatılmıştır. Günümüzde trafolarda halen kullanılmakta olan silisli saçların yerine ferrobor, kobaltbor ve nikelbor ön alaşımlarından imal edilen trafo saçlarının kullanımı ile trafolarda çekirdek kayıpları $\% 80$ oranında azalmaktadır. Ayrıca bu alaşımların, klasik silisli saçların yerine kullanımı ile sadece ABD'de 60 Milyar kWh enerjinin tasarruf edilebileceği ve enerji üretimi esnasında açığa çıkan $\mathrm{CO}_{2}$ 'de 40 milyon ton, $\mathrm{SO}_{2}$ 'de ise 1 milyon ton azalma olacağı hesaplanmıştır. Böylece ABD'de yıllık 200 milyon USD tasarruf yapılırken, çevre kirliliği de önemli ölçüde azalmaktadır [3, 4].

Son yıllarda, geçiş metali borürlerinden biri olan CoB'nin nikel bazlı ikincil pillerde, yüksek deşarj kapasitesi ve mükemmel çevrim performansı sayesinde sıklıkla bir anot malzemesi olarak kullanıldığg literatürde görülmektedir [5-9]. Öte yandan, birçok araştırmacı CoB alaşımlarının alkali ortamda yüksek deşarj kapasitesi gösterdiğini, bu yüksek enerji yoğunluğunun anotlarda kullanım imkânı sunduğunu ve bor hidrürlerinin hidrolizi yoluyla hidrojen üretimi için katalizörler olarak kullanılabileceğini göstermiştir [6-10].

\section{Literatür Özeti}

Metalik malzemelerin yüksek sıcaklık, korozif ortam ve yüksek strese maruz kalması sonucunda ortaya çıkan en büyük sorunlarından biri yüzey bozunmasıdır. Bu malzemelerin yüzeyinde oluşan tahribat, sertlik ve aşınma direnci gibi mekanik özelliklerinde önemli ölçüde bir azalmaya neden olup, arızalara sebebiyet vermektedir. Yüzey bozulmasını önlemek ve metal parçaların kullanım ömrünü arttırmak için genellikle fonksiyonel kaplamalar yapılarak metal yüzeyler korunur. $\mathrm{Bu}$ kaplamalar genel olarak nikel, kadmiyum ya da krom esaslıdır. Krom kaplamaların sertliği 600 ile 1000 HV arasında değişmektedir. Nikel esaslı kaplamalarda sertlik değeri 1300 HV'e kadar yükselmektedir. Hernandez ve arkadaşları tarafından yapılan çalışmada, CoB kaplamalarda sertlik, değişen sıcaklıklarla 800 ila $1280 \mathrm{HV}$ aralığında değişmektedir. Bu değer NiB kaplamalara denk bir dayanım sağlarken, Cr'li kaplamalara göre oldukça yüksektir. Ancak nikel, Amerikan Çevre Koruma Ajansına [(the U.S. Environmental Protection Agency (EPA)] EPA listesine göre öncelikli bir kirletici olarak görülmekte ve en zehirli 14 ağır metalden biri olarak kabul edilmektedir. Son zamanlarda, Prado ve ark. yüksek sertlik ve düşük aşınma oranlarından dolayı sert krom kaplamalara bir alternatif olarak nanokristal kobalt fosforlu (nCo-P) kaplamaları geliştirmişlerdir. Kobaltın insan sağlığını olumsuz yönde etkileyen ağır bir metal olarak görülmemesi, bu kaplamaları krom ve nikel bazlı olanlara göre avantajlı kılmaktadır [11-22].

Kobalt alaşımları iyi özelliklerine rağmen, termal ve aşındırıcı etkilerin etkin olduğu ortamlarda korozyon dayanımının yetersiz kaldığı görülmüş, bu alaşımların yüzey özelliklerini geliştirebilmek için borlama işlemine başvurulmuştur. $\mathrm{Bu}$ işlemde bor atomları $\mathrm{Co}$ alaşımlarının yüzeyinden yayınarak CoB fazlarını oluşturmaktadırlar [23-28]. CoB faz diyagramına göre alaşım ağırlıkça minimum \%15,5 B içerirken, sertliği 18 ila $20 \mathrm{GPa}$ aralığındadır. Alaşımın kristal yapısı tetragonal hacim merkezlidir. 
Türkiye, Dünya'da en fazla bor rezervine sahip olan ülkedir. Ülkemizde bor içeren ileri teknoloji ürünlerin geliştirilmesi ve üretilmesi Türkiye'ye daha fazla katma değer sağlayabilecektir [29]. Bu çalışmada, metalotermik redüksiyon yöntemiyle oksitli kobalt ve bor bileşiklerinden CoB alaşımlarının üretimi gerçekleştirilmiştir. Oksitli hammaddeleri redükleyebilmek için aluminyum kullanılmış, değişen redüktan stokiyometrilerinde deneyler yapılmıştır. Redüksiyon deneyleri yapılmadan önce sistem termodinamik olarak modellenmiş, deneysel çalışmalar elde edilen sonuçlara göre kurgulanmıştır.

\section{Materyal ve Metot}

\subsection{Materyal}

Metalotermik redüksiyon yöntemi ile kobalt ve bor esaslı alaşımların üretimi için çalışmalar yapılmıştır. Deneysel çalışmalar, boroksit $\left(\mathrm{B}_{2} \mathrm{O}_{3}\right)$ ve kobalt oksitin $\left(\mathrm{Co}_{3} \mathrm{O}_{4}\right)$ alüminyum ile redüklenip alaşım elde edilmesini kapsamaktadır. Deneysel çalışmalardaki amaç, karbotermik yöntemle üretilen alaşımların safiyetine uygun kalite standartlarında Co ve B esaslı alaşımlar elde etmektir. Deneysel çalışmalarda kullanılan ve yüksek safiyetlere sahip hammaddeler Nanokar firmasından temin edilmiş olup hammaddelerin safiyet ve ortalama partikül boyutu değerleri Tablo 1 'de verilmiştir.

Tablo 1. Deneysel çalışmalarda kullanılan hammaddelerin safiyet ve ortalama partikül boyutu değerleri.

\begin{tabular}{ccc}
\hline Bileșen & Safiyet, \% & OPB, $\boldsymbol{\mu m}$ \\
\hline $\mathrm{B}_{2} \mathrm{O}_{3}$ & 97,00 & $<53$ \\
$\mathrm{Co}_{3} \mathrm{O}_{4}$ & 99,70 & $<38$ \\
$\mathrm{Al}$ & 99,50 & $<45$ \\
\hline \multicolumn{3}{c}{${ }^{* \text { OPB: Ortalama Partikül Boyutu }}$}
\end{tabular}

\subsection{Metot}

Metalotermik redüksiyon, metallerin ve alaşımların üretiminde kullanılabilen ekzotermik karakterli, basit, hızlı, maliyeti düşük, karmaşık pota ve firın sistemleri içermeyen ve kullanışlı bir yöntemdir [30, 31]. Ayrıca, metalotermik redüksiyon esaslı ve yanma sentezi (combustion synthesis, CS) genel ismi ile isimlendirilen prosesler ile de karbür, nitrür, borür vb. esaslı ileri seramiklerin ve intermetaliklerin sentezi de mümkündür. Yanma sentezi prosesinin alt grupları, kendiliğindenilerleyen yüksek-sicaklık sentezi (self-propagating high-temperature synthesis, SHS), hacim yanma sentezi (volume combustion synthesis, VCS) ve çözelti yanma sentezidir (solution combustion synthesis, SCS). Illk iki proses ekzotermik katı hal reaksiyonları üzerinden gerçekleşirken, SCS çözeltilerdeki bileşenlerin ekzotermik reaksiyonları üzerinden gerçekleşmektedir [32-34].

Metalotermik redüksiyon esaslı proseslerde, reaksiyonların ekzotermik olması, dışarıdan 1Sı vermeden reaksiyonların kendiliğinden gerçekleşmesine neden olmakta ve proseslerdeki 1sıtma maliyetlerini ortadan kaldırmaktadır. Bu yöntemde reaksiyon, reaktan karışımındaki metal oksitin metalinin oksijene ilgisi daha fazla olan bir metal tarafından redüklenmesiyle gerçekleşmektedir. $\mathrm{Bu}$ yöntemde indirgeyici metal maliyeti ve ürünlerde redüktan metal kontaminasyonu gibi dezavantajlar bulunsa da reaksiyonun ekzotermik doğası ve dışarıdan ilave enerjiye gerek duymaması önemli bir avantaj arz etmektedir. $\mathrm{Bu}$ avantajlarından dolayı $\mathrm{CoB}$ ön alaşımlarında üretim tekniği olarak metalotermik redüksiyon yöntemi seçilmiştir [30-34]. Gerçekleştirilen çalışmalar, termokimyasal modellemeler, deneysel çalışmalar ve karakterizasyon çalışmaları olmak üzere üç ana başlıkta toplanmış ve iş-akış şeması Şekil 1'de verilmiştir.

Deneysel çalışmalar, Yalova Üniversitesi Ekstraktif Metalurji ve Geri Dönüşüm Laboratuvarı'nda (EMR-Lab) gerçekleştirilmiştir. CoB ön alaşımlarının üretim çalışmaları, reaktan toz karışımlarının 
Eşitlik 1 ve Eşitlik 2'de gösterilen reaksiyonların bir karışımı olarak son üründe ağırlıkça \%16 B sağlayacak şekilde yapılmıştır.

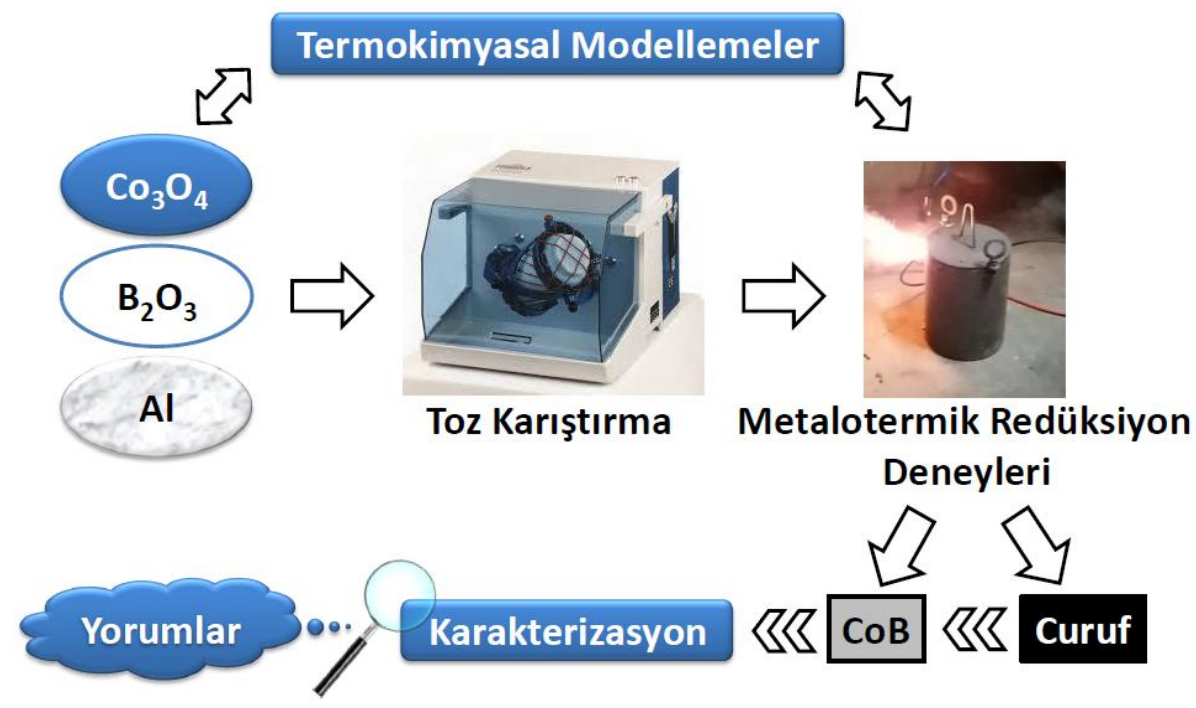

Şekil 1. Deneysel çalışmaların iş-akış şeması.

Deneysel çalışmalar açık atmosfer altında ve Al stokiyometrisi \%100'den \%115'e kadar artan oranlarda yürütülmüştür.

$$
\begin{gathered}
3 \mathrm{Co}_{3} \mathrm{O}_{4}+8 \mathrm{Al} \rightarrow 9 \mathrm{Co}+4 \mathrm{Al}_{2} \mathrm{O}_{3} \\
\mathrm{~B}_{2} \mathrm{O}_{3}+2 \mathrm{Al} \rightarrow 2 \mathrm{~B}+\mathrm{Al}_{2} \mathrm{O}_{3}
\end{gathered}
$$

$\mathrm{CoB}$ ön alaşımlarının üretimi için yapılan çalışmalarda, ilk olarak hammaddeler $105{ }^{\circ} \mathrm{C}$ 'de 2 saat boyunca etüvde kurutularak nemden arındırılmıştır. \%100 Al stokiyometrisindeki deneysel çalışmada reaktan toz karışımının ağırlığı 100 gram olacak biçimde hazırlanmıştır. Karışımlar metalik bir kaba yerleştirilip turbula üç eksenli karıştırıcıda $15 \mathrm{dk}$. süreyle karıştırılarak şarjın homojen olması sağlanmıştır. Homojen karışım bakır pota içerisine konulmuş ve şarjın yüzeyine reaksiyonları başlatmak için bir güç kaynağına bağlı $\mathrm{Cr}-\mathrm{Ni}$ direnç teli yerleştirilmiştir.

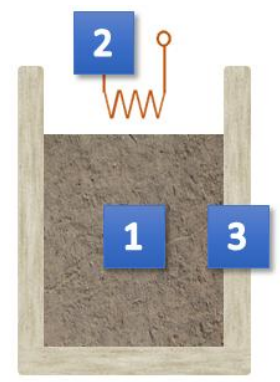

A

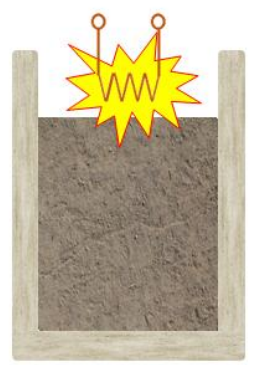

B

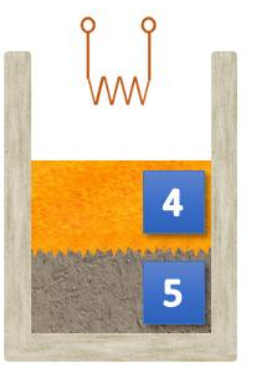

C

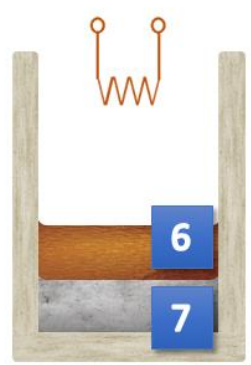

D

Şekil 2. Deneysel çalışmaların şematik gösterimi: [A] reaktan toz karışımının reaksiyon potasına yerleştirilmesi (1: reaktan karışımı, 2: direnç teli, 3: bakır pota), [B] reaksiyonun başlatılması, [C] yanma dalgasının ilerlemesi (4: reaksiyona girmiş ve 5: reaksiyona girmemiş hammaddeler) ve [D] reaksiyon ürünleri (6: curuf, 7: metal). 
Güç kaynağına bağlı direnç telinden elektrik akımı geçirilerek reaksiyonların tetiklenmesini sağlanmıştır. Toz karışımının üst kısmında oluşan 1sı dalgası, şarj boyunca yayılarak redüksiyon reaksiyonları gerçekleştirilmiştir. Redüksiyon reaksiyonlarından sonra bakır potalar suda soğutulmuş ve ürünler (metal ve curuf) mekanik olarak potalardan çıkarılmıştır. Metalotermik deneysel çalışmaların şematik görünümü Şekil 2'de verilmiştir.

SEM ve optik mikroskop ile mikro yapı görüntüleme çalışmaları gerçekleştirilmiştir. $\mathrm{Bu}$ ekipmanlarda görüntü alabilmek için numuneler 240, 320, 600 ve 1000 grid aşındırıcı boyutlarında zımparalanıp, parlatma işlemine tabi tutulmuştur. Parlatılmış numuneler, $30 \mathrm{ml} \mathrm{saf} \mathrm{su,} 10 \mathrm{ml} \mathrm{HCl}$, $10 \mathrm{ml} \mathrm{HNO} 3$ içeren çözeltide dağlanarak, görüntülenmeye hazır hale getirilmiştir.

\subsection{Analiz Yöntemleri}

Deneysel çalışmaların termokimyasal olarak modellenmesi FactSage 7.1 programı ile yapılmıştır. Üretilen alaşımların bileşimlerinin belirlenmesinde X-1şınları difraksiyon spektrometresi (XRD, PANalytical PW3040/60 - Cu K $\alpha$ ) kullanılmış ve elde edilen paternler X'Pert High Score veri tabanı ile yorumlanmıştır. Alaşımların metalografik yüzey hazırlama işlemlerinden sonra mikroyapı görüntüleri YAMER marka optik metalurji mikroskobu ile alınmıştır. Alaşımların taramalı elektron mikroskobu ile de mikroyapı görüntüleri elde edilmiş ve EDS yöntemi ile alaşımların nicel analizleri gerçekleştirilmiştir (SEM-EDS, Zeiss - Gemini 500). Mikro vickers yöntemi ile elde edilen alaşımların sertlik değerleri ölçülmüştür (HV1, QNESS - Q250C).

\section{Bulgular ve Tartışma}

Alüminotermik yöntem ile $\mathrm{CoB}$ alaşımı üretmek için yapılan deneylere eş zamanlı olarak, redüksiyon sistemi, FactSage 7.1 programiyla termokimyasal olarak modellenmiştir. Termokimyasal modelleme çalışmalarında ilk olarak artan aluminyum miktarıyla redüksiyon sisteminin adyabatik sıcaklık değişim simülasyonu gerçekleştirilmiş ve bulgular Şekil 3'te verilmiştir.

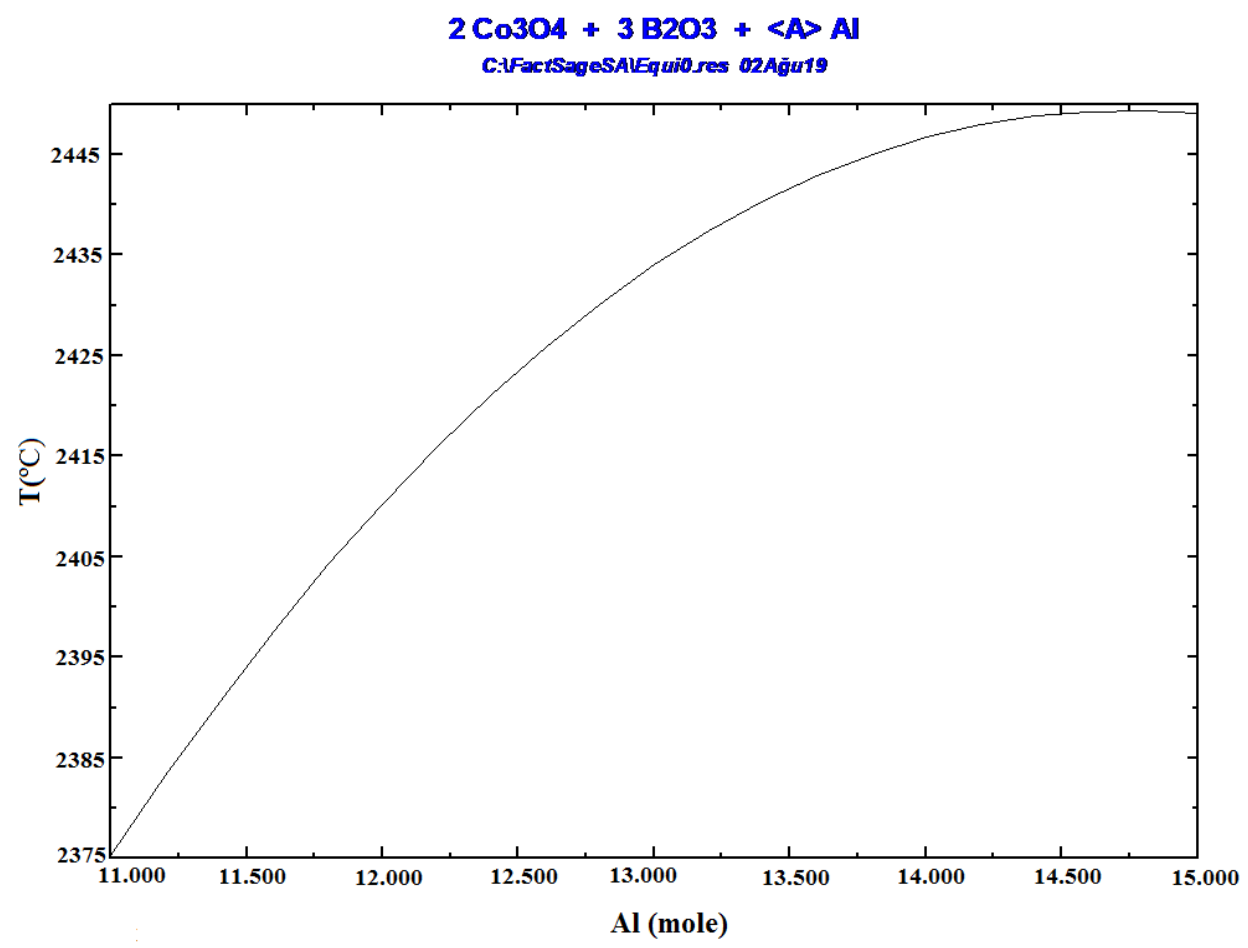

Şekil 3. Artan Al miktarıyla redüksiyon sisteminin adyabatik sıcaklık değişimi. 
Metalotermik reaksiyonlarda adyabatik sicaklık, reaksiyonun kendi kendine ilerleyebilmesi için önemli bir parametredir ve minimum $1527^{\circ} \mathrm{C}$ olması gerekmektedir $[30,32]$. Şekil 3 incelendiğinde artan Al stokiyometrisiyle sicaklığın $2375^{\circ} \mathrm{C}$ 'den $2500^{\circ} \mathrm{C}^{\prime}$ ye kadar yükseldiği belirlenmiştir. $\mathrm{Bu}$ değer reaksiyonun kendi kendine ilerlemesi için yeterli koşulları sağlamaktadır.

Redüksiyon sisteminin adyabatik sicaklığı belirlendikten sonra, değișen aluminyum stokiyometrisiyle oluşacak muhtemel fazlar FactSage 7.1 programının 'Equlibrium Modülü', kullanılarak modellenmiştir. Termodinamik incelemeler esnasında equilibrium modülü kullanılırken, FT oxide ve SGTE databaselerinden faydalanılmıştır. Modelleme sonucu elde edilen bulgular, Şekil 4'te verilmiştir. Şekil 4'te elde edilen sonuçlar adyabatik sistemde oluşan muhtemel fazları göstermektedir. İlgili şekilden artan alüminyum miktarında, kobaltın sabit bir biçimde elde edilebildiği görülmüştür, artan Al miktarıyla yapıda oluşacak bor miktarının da buna paralel olarak arttığı görülmüştür. $\mathrm{Bu}$ sebeple deneysel çalışmalar tasarlanırken $\mathrm{B}_{2} \mathrm{O}_{3}$ bileşiğindeki B'yi daha yüksek verimlerde redükleyebilmek için Al stokiyometrisi ağırlıkça \%5'lik miktarlarda arttırılması planlanmıştır.

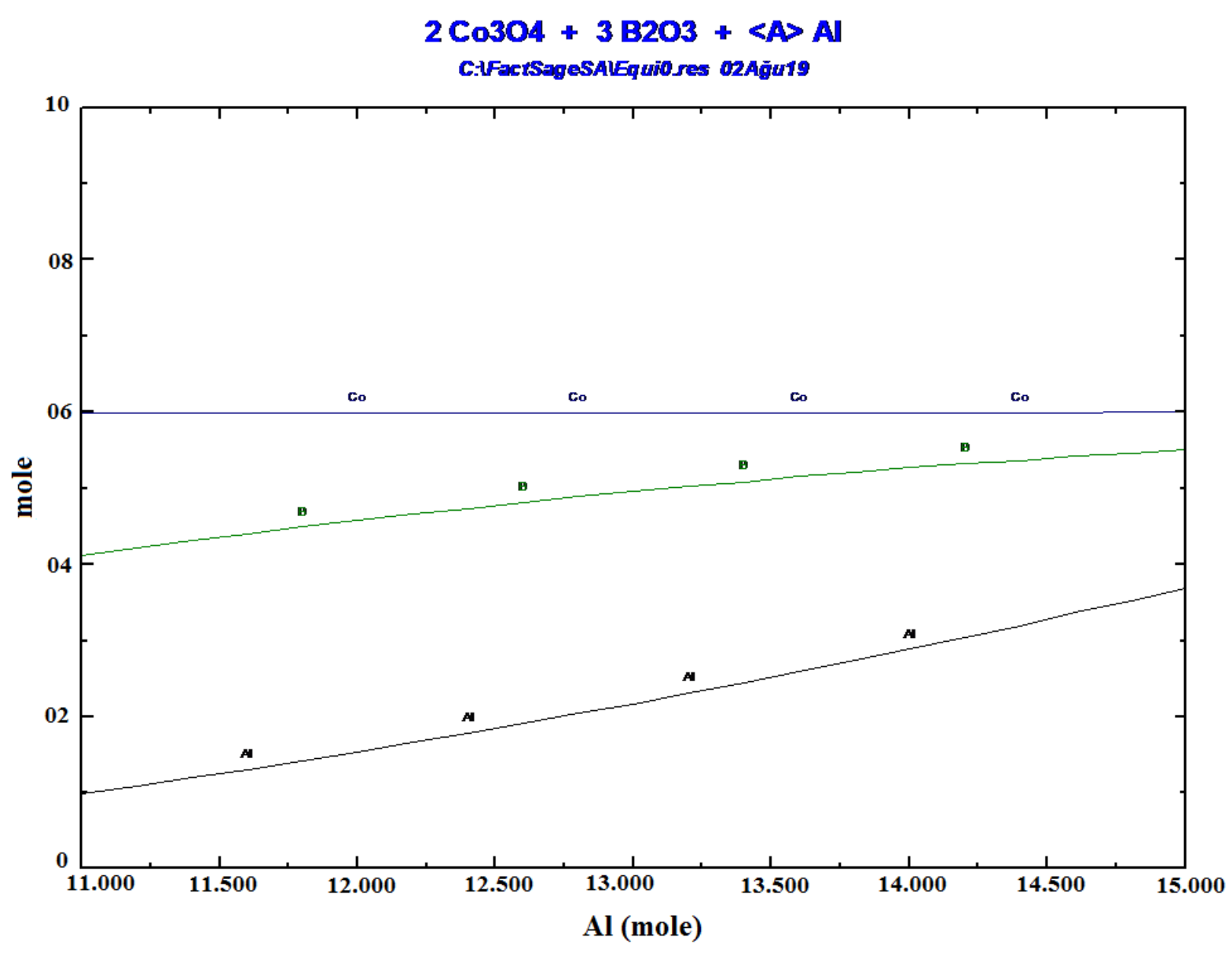

Şekil 4. Artan Al miktarıyla redüksiyon sisteminde oluşan muhtemel fazlar.

Redüksiyon sistemi termokimyasal olarak incelendikten sonra deneysel çalışmalara geçilmiştir. Deneysel çalışmalarda kobaltı ve ağ.\%16 boru redükleyebilecek alüminyum miktarı \%100 stokiyometrik oran olarak belirlenmiş, bor verimini arttırabilmek için deneyler sırasıyla \%105, $\% 110$ ve \%115'lik Al stokiyometrik oranlarında tekrarlanmıştır. Deneyler sonucunda ağırlıkça oluşan metal, curuf ve saçılma miktarları Şekil 5'te paylaşılmıştır. Metalotermik reaksiyonlar 
şiddetli ve ekzotermik karakterli olduğundan bir miktar saçılma, bu tip reaksiyonlarda kaçınılmaz olarak ortaya çıkmaktadır. İlgili şekilde oluşan curuf oranlarının artan Al stokiyometrisiyle düştüğü, buna paralel olarak elde edilen alaşım miktarının arttığı görülmektedir. Bu durum kimyasal modellemelerdeki Al miktarının artışı ile bor redüksiyon veriminin arttığı sonucu ile de uyumludur. Ayrıca Şekil 5'te \%110 ve \%115 Al stokiyometrisi ile yürütülen deneysel çalışmalarda ürün ağırlıklarında kayda değer bir değişimin olmadığı tespit edilmiş ve bu yüzden daha yüksek aluminyum stokiyometrilerinde deneysel çalışmalara devam edilmemiştir. Deneyler sonucunda oluşan saçılma oranları, artan enerji miktarına bağlı olarak \%110 ve \%115 stokiyometrik Al içeren deneylerde artış göstermiş, bu da oluşan metal miktarını olumsuz etkilemiştir.

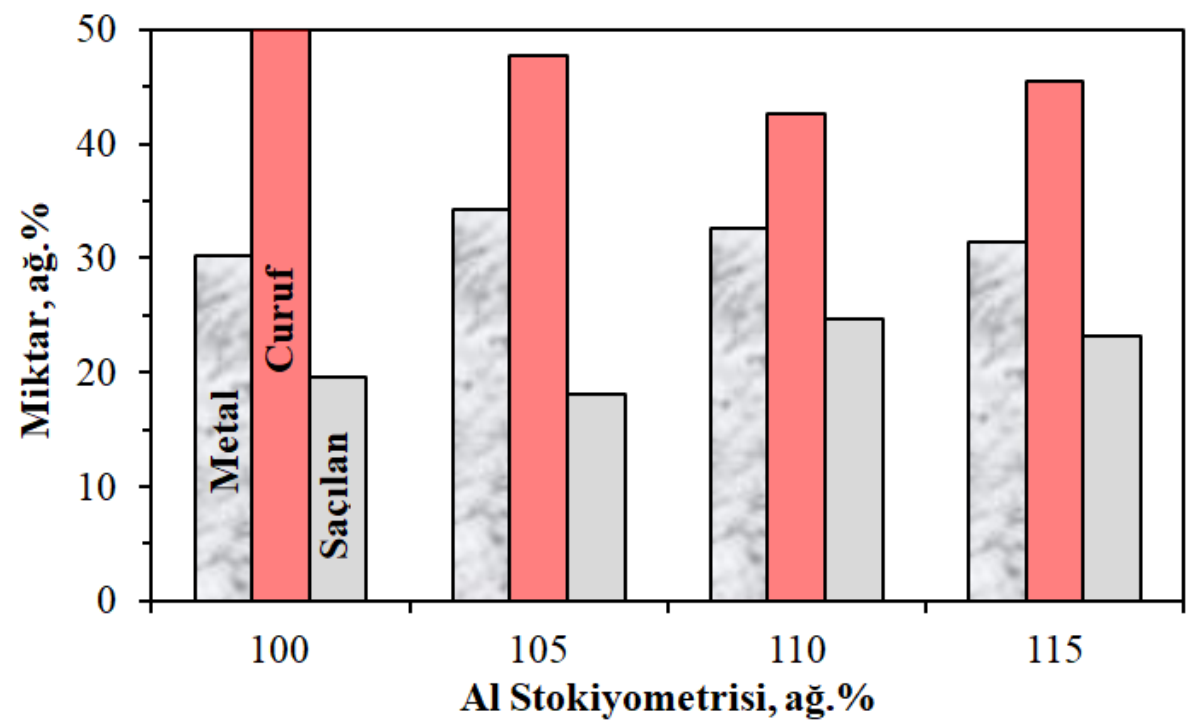

Şekil 5. Metalotermik redüksiyon deneyleri sonucunda ürünlerin dağılımının artan Al redüktan stokiyometrisi ile değişimi (ağ.\%).

Metalotermik redüksiyon deneyleri sonucunda ürünlerin dağılımı incelendikten sonra, alaşımların bileşimsel karakterizasyonu XRD yöntemiyle yapılmış ve bulgular Şekil 6'da verilmiştir.

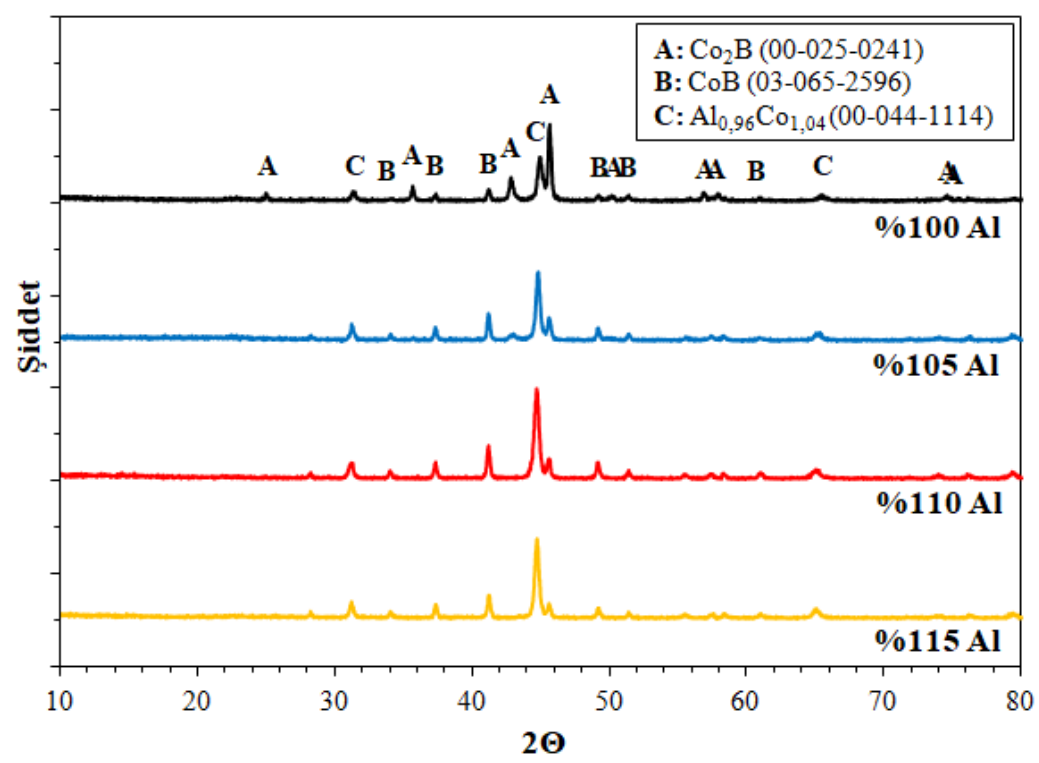

Şekil 6. Üretilen CoB alaşımlarının XRD paternleri. 
Bütün ürünlerde $\mathrm{Co}_{2} \mathrm{~B}, \mathrm{CoB}$ ve $\mathrm{Al}_{0,96} \mathrm{Co}_{1,04}$ fazlarının oluştuğu tespit edilmiştir. XRD paternindeki verilere göre \%100 stokiyometrik alüminyum içeren bileşende $44^{\circ}$ ' de oluşan $\mathrm{Al}_{0,96} \mathrm{Co}_{1,04}$ fazının diğer deneylerde şiddetini arttırarak oluştuğu belirlenmiş, buna göre artan aluminyum miktarının $\mathrm{Al}_{0,96} \mathrm{Co}_{1,04}$ fazının oluşumunu teşvik ettiği anlaşılmıştır. Bu sonuçlara göre $\mathrm{Co}$ ve $\mathrm{B}$ içeren $\mathrm{Co}_{2} \mathrm{~B}$ ve CoB fazlarının en yüksek oranda $\% 100$ stokiyometrik bileşimde elde edildiği belirlenmiştir. Her ne kadar metal oluşum miktarları artan stokiyometrilerde yükselse de, arzu edilen bileşime en yakın sonucun \%100 stokiyometrik oranda elde edildiği gözlemlenmiştir.

Karakterizasyon çalışmalarının bir sonraki aşamasında ürünlerin mikroyapı görüntüleri optik metalurji mikroskobuyla görüntülenmiş ve sonuçlar Şekil 7'de paylaşılmıştır. XRD sonuçlarından hareketle, açık renkte görülen bölgelerin $\mathrm{CoB}$ fazlarından oluştuğu, daha koyu bölgelerin $\mathrm{Al}$ içeren $\mathrm{Al}_{0,96} \mathrm{Co}_{1,04}$ fazından oluştuğu düşünülmektedir. Çünkü koyu renkli fazın artan Al stokiyometrisi ile arttığı gözlemlenmiştir. Mikrograflarda siyah renkte (en koyu) görülen bölgeler, numune hazırlama esnasında yapılan sıcak kalıplama işleminden kalan ve giderilemeyen polimer kalıntılarıdır. $\mathrm{Bu}$ kalıntılar, oluşan alaşımların gözenekli ve çok sert olmalarından dolayı zımparalama ve parlatma işlemlerinde tam olarak giderilememişlerdir.
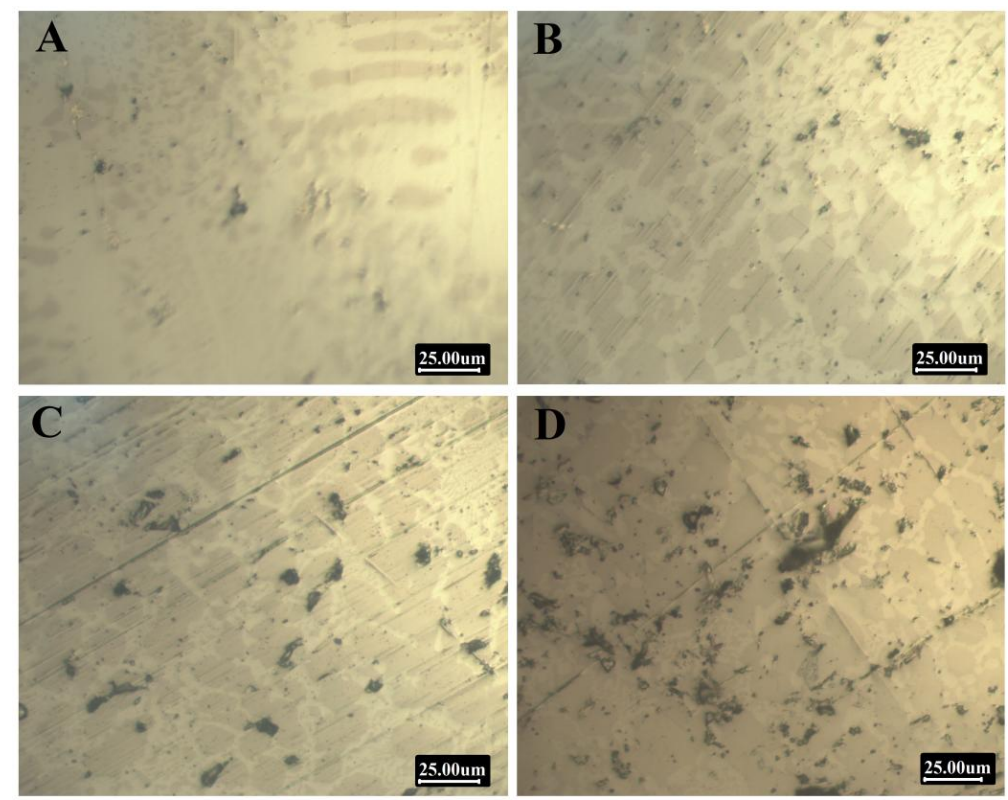

Şekil 7. CoB alaşımlarının optik mikroskop mikrografları (400X): (A) \%100, (B) \%105, (C) \%110, (D) $\% 115 \mathrm{Al}$ stokiyometrisi.

Ürünlerin oluşum oranları, fazları ve mikro yapılarının çözümlenmesinin ardından sertlik değerleri de ölçülmüş ve sonuçlar Şekil 8'de verilmiştir. Sertlik değerleri, QNESS - Q250C model test cihazıyla belirlenirken, yükleme standartlara uygun biçimde cihaz tarafindan otomatik olarak yapılmıştır. Deneyler 5'er kez tekrar edilip, ortalama sertlik değerlerine ulaşılmıştır. Sertlik sonuçları incelendiğinde \%100 stokiyometrik alaşımda $950 \mathrm{HV} 1$ değeri elde edilirken \%105, \%110 ve \%115 alüminyum stokiyometrisi ile gerçekleştirilen deneylerde sirasıly 703,848 ve 818 HV1 değerlerine ulaşılmıştır. Alaşımların bileşiminde bulunan alüminyum miktarının ve dolayısıyla $\mathrm{Al}_{0,96} \mathrm{Co}_{1,04}$ fazının artışıyla sertlik değerlerinde düşüş meydana geldiği belirlenmiştir.

Üretilen alaşımların SEM mikrografları Şekil 9'da, EDS sonuçları ise Tablo 2'de paylaşılmıştır. EDS sonuçları incelendiğinde, artan Al stokiyometrisi ile alaşımlarda B konsantrasyonunun 100\% Al stokiyometrisinde ağ.\%13,62'den \%115 Al stokiyometrisinde \%17,35'e kadar yükseldiği görülmektedir. Buna karşılık artan Al stokiyometrisi ile alaşımların Al içerikleri de yükselmektedir. 
$\mathrm{Bu}$ değer, \%100 Al stokiyometrsisinde \%6,54 iken \%115 Al stokiyometrisinde \%13,31'e kadar yükselmiştir ve alaşımların safiyetini düşürdüğü için istenmeyen bir durumdur.

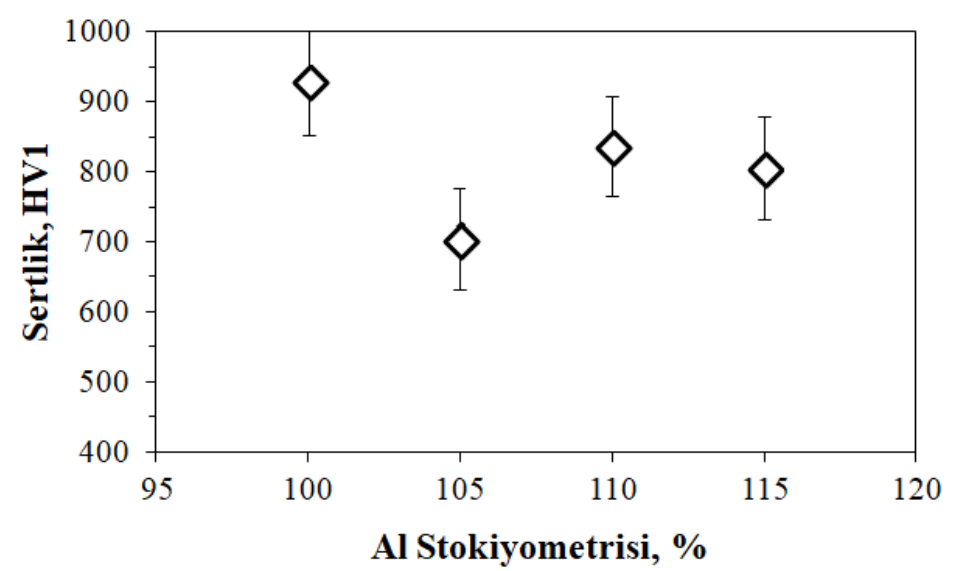

Şekil 8. CoB alaşımlarının mikro vickers (HV1) sertlik sonuçları.

Ayrıca, alaşımların saflığını negatif yönde etkileyen bir bileşen olarak tüm alaşımlarda düşük oranlarda da olsa da $\mathrm{Cu}$ mevcudiyeti de gözlemlenilmiştir. Cu'nun $\mathrm{Ni}-\mathrm{Cr}$ direnç telinin güç kaynağına bağlandığı bakır kablodan kaynaklandığı düşünülmektedir. İleri çalışmalarda, reaksiyonları tetiklemek için lazer sistemi kullanılabilirse bu tip kontaminasyonların da önüne geçilebileceği öngörülmektedir.
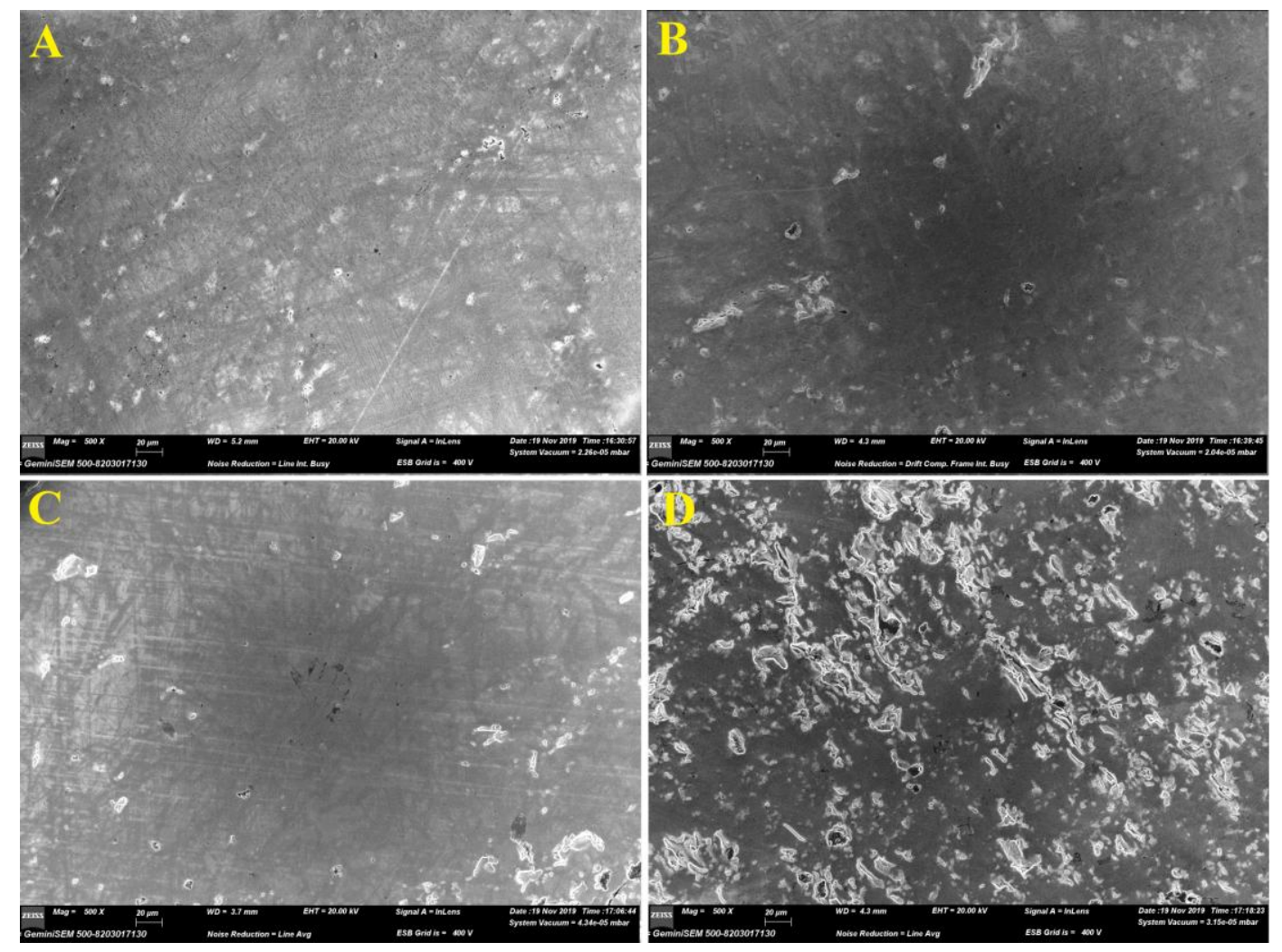

Şekil 9. CoB alaşımlarının SEM mikrografları (500X): (A) \%100, (B) \%105, (C) \%110, (D) \%115 Al stokiyometrisi. 
Tablo 2. Artan Al stokiyometrisi ile üretilen CoB alaşımlarının EDS sonuçları (ağ.\%).

\begin{tabular}{ccccc}
\hline \multirow{2}{*}{ Element } & \multicolumn{4}{c}{ Al stokiyometrisi, \% } \\
\cline { 2 - 5 } & $\mathbf{1 0 0}$ & $\mathbf{1 0 5}$ & $\mathbf{1 1 0}$ & $\mathbf{1 1 5}$ \\
\hline $\mathrm{Co}$ & 73,39 & 68,05 & 67,64 & 66,13 \\
$\mathrm{~B}$ & 13,62 & 16,69 & 17,44 & 17,35 \\
$\mathrm{Al}$ & 6,54 & 11,34 & 12,13 & 13,31 \\
$\mathrm{Cu}$ & 4,39 & 3,64 & 3,09 & 3,32 \\
\hline
\end{tabular}

\section{Sonuç ve Öneriler}

$\mathrm{Bu}$ çalışmada $\mathrm{CoB}$ ön alaşımlarının alüminotermik (metalotermik) yöntem ile üretimi amaçlanmış, reaksiyon koşulları FactSage 7.1 termokimyasal simülasyon programıyla modellenmiştir. Çalışmada hammadde karışımdaki metal-metaloid oksitlerin $\left(\mathrm{Co}_{3} \mathrm{O}_{4}, \mathrm{~B}_{2} \mathrm{O}_{3}\right)$ metal-metaloid içerikleri artan stokiyometrilerde (ağ.\%100'den \%115'e kadar) alüminyum ile redüklenerek oluşan alaşım, curuf ve saçılma miktarları incelenmiş ve ürünler karakterize edilmiştir. Yapılan karakterizasyonlar sonucunda artan Al stokiyometrisi ile oluşan alaşım miktarının arttı̆̆ ve curuf miktarının azaldığı tespit edilmiştir. Deneysel çalışmalarda, artan Al stokiyometrisi ile termokimyasal incelemelerdeki bulgulara paralel olarak ortaya çıkan reaksiyon isısının arttığı, bunun sonucunda da saçılma oranlarının yükseldiği tespit edilmiştir. Üretilen alaşımların XRD analizleri, optik mikroskop ve SEM-EDS sonuçlarından, alaşımlarda Co ve B içeren fazların $\left(\mathrm{Co}_{2} \mathrm{~B}\right.$, $\mathrm{CoB}$ ) yanı sıra $\mathrm{Al}_{0,96} \mathrm{Co}_{1,04}$ fazının da oluştuğu görülmüsştür. Artan $\mathrm{Al}$ stokiyometrisi ile $\mathrm{Al}_{0,96} \mathrm{Co}_{1,04}$ miktarının arttığı belirlenmiştir. Metalotermik redüksiyon ve metalotermik redüksiyon esaslı prosesler (SHS, VCS, SCS), basit, hızlı ve yatırım maliyetleri düşük prosesleridir. Ayrıca, redüktan olarak karbon kullanılmadığından bu proseslerde, karbon salınımı bulunmamaktadır ve çevre dostu üretim yöntemleridir. En büyük dezavantajları, redüktan maliyetleri ve redüktan malzemenin son ürünü geçebilmesidir. Bu çalışmada $\% 100 \mathrm{Al}$ stokiyometrisi ile gerçekleştirilen deneysel çalışmada ağırlıkça \%73,39 $\mathrm{Co}, \% 13,62 \mathrm{~B}$ ve \%6,54 Al içeren bir alaşım üretilmiştir. İleri deneysel çalışmalarda farklı metal redüktanların tek başlarına veya Al ile bir arada kullanılmasının, daha düşük redüktan kontaminasyonuna sahip alaşımların elde edilebilmesini sağlayacağı düşünülmektedir. Bu çalışmada araştırılan alüminotermik $\mathrm{CoB}$ üretiminin literatürde bulunmaması, bu konuda yapılacak ileri çalışmalara 1şık tutacak nitelikte olduğu kanaatini oluşturmaktadır.

\section{Teșekkür}

Yazarlar, termokimyasal modellemeler ve SEM-EDS karakterizasyonlarındaki yardımlarından dolayı Faruk Kaya’ya (İTÜ) ve Serkan Başlayıcı'ya (İ.Medipol Ü.) teşekkür eder.

\section{Kaynaklar}

[1]. Yücel, O., Addemir, O., Tekin, A., 1992, "The Optimization of Parameters for The Carbotermic Production of Ferroboron", INFACON 6. Cape Town, Vol. 1, 1992, pp. 285289.

[2]. US 4133681 Allied Chemical Corp. Jan. 1979.

[3]. Hasegawa, R., 1981, "Aplication of Rapidly Solidified Metals in USA and in Japan", Allied Signal Inc. Metglass Products, 6 Eastmas Road, Rapsippony NJ 0705 Y, USA.

[4]. Jaschinski, W. 1981, “Amorphe Metalle-Entwickking Einer Neuen Werkstoffklasse”, Tech. Mitt. Krupp, Forsch.Ber. Band 39. 1t. 1.

[5]. Mitov, M., Popov, A., Dragieva, I., Nanoparticles produced by borohydride reduction as precursors for metal hydride electrodes, Journal of Applied Electrochemistry, 1999, 29(1) 5963. DOI: https://doi.org/10.1023/A:1003439301820 
[6]. Wang, Y. D., Ai, X. P., Yang, H. X., Electrochemical hydrogen storage behaviors of ultrafine amorphous Co-B alloy particles, Chemistry of Materials, 2004, 16(24), 5194-5197. DOI: https://doi.org/10.1021/cm049252f

[7]. Wang Y.D., Ai X.P., Cao Y.L., Yang H.X., Exceptional electrochemical activities of amorphous $\mathrm{Fe}-\mathrm{B}$ and $\mathrm{Co}-\mathrm{B}$ alloy powders used as high capacity anode materials, $\begin{array}{lllll}\text { Electrochemistry } \quad \text { Communications, } & \text { 2004, 6(8), } & \text { DOI: }\end{array}$ https://doi.org/10.1016/j.elecom.2004.06.002

[8]. Tong, D. G., Chu, W., Zeng, X. L., Tian, W., Wang, D., Synthesis of mesoporous Co-B alloy in room-temperature ionic liquids and its electrochemical properties, Materials Letters, 2009, 63(17), 1555-1557. DOI: https://doi.org/10.1016/j.matlet.2009.04.016

[9]. Lu, D. S., Li, W. S., Jiang, X., Tan, C. L., Zeng, R. H., Magnetic field assisted chemical reduction preparation of Co-B alloys as anode materials for alkaline secondary battery, Journal of Alloys and Compounds, 2009, 485(1-2), 621-626. DOI: https://doi.org/10.1016/j.jallcom.2009.06.060

[10]. Patel, N., Miotello, A., Progress in Co-B related catalyst for hydrogen production by hydrolysis of boron-hydrides: a review and the perspectives to substitute noble metals, International Journal of Hydrogen and Energy, 2015, 40(3), 1429-1464. DOI: https://doi.org/10.1016/j.ijhydene.2014.11.052

[11]. Hernandez, A. M., Albores, A. M., Duran, E. A., Flores, J. G., Bueno, J. J. P., Meas, Y., Trejo, G., Effect of heat treatment on the hardness and wear resistance of electrodeposited CoB alloy coatings, Journal of Materials Research and Technology, 2019, 8(1), 960-968. DOI: https://doi.org/10.1016/j.jmrt.2018.07.007

[12]. Prado, R. A., Facchini, D., Mahalanobis, N., Gonzalez, F., Palumbo, G., 2009, Electrodeposition of nanocrystalline cobalt alloy coatings as a hard chrome alternative, In: 2009 DoD Corrosion Conference, 1-13.

[13]. Huang, Y. S., Cui, F. Z., Effect of complexing agent on the morphology and microstructure of electroless deposited Ni-P alloy, Surface and Coatings Technology, 2007, 201(9-11), 54165418. DOI: https://doi.org/10.1016/j.surfcoat.2006.07.189

[14]. Alirezaei, S., Monirvaghefi, S. M., Salehi, M., Saatchi, A., Wear behavior of Ni-P and Ni-P$\mathrm{Al}_{2} \mathrm{O}_{3}$ electroless coatings, Wear, 2007, 262(2), 978-85. DOI: https://doi.org/10.1016/j.wear.2006.10.013

[15]. Monteiro, O. R., Murugesan, S., Khabashesku, V., Electroplated Ni-B and Ni-B metal matrix diamond nano composite coatings, Surface and Coatings Technology, 2015, 272(1), 291-297. DOI: https://doi.org/10.1016/j.surfcoat.2015.03.049

[16]. Ogihara, H., Udagawa, K., Saji, T., Effect of boron content and crystalline structure on hardness in electrodeposited Ni-B alloy films, Surface and Coatings Technology, 2012, 206(11-12), 2933-2940. DOI: https://doi.org/10.1016/j.surfcoat.2011.12.025

[17]. López, J. R., Méndez, P. F., Pérez-Bueno, J. J., Trejo, G., Stremsdoerfer, G., Meas, Y., The effect of boron content, crystal structure, crystal size on the hardness and the corrosion resistance of electrodeposited Ni-B coatings, International Journal of Electrochemical Science, 2016, 11(1), 4231-4244. DOI: https://doi.org/10.20964/2016.06.23

[18]. Nava, D., Dávalos, C. E., Martínez-Hernández, A., Manríquez, F., Meas, Y., Ortega-Borges, R., Pérez-Bueno, J. J., Trejo, G., Effects of heat treatment on the tribological and corrosion properties of electrodeposited Ni-P alloys, International Journal of Electrochemical Science, 2013, 8(1), 2670-2681.

[19]. Ziyuan, S., Deping, W., Zhimin, D., Surface strengthening pure copper by Ni-B coating, Applied Surface Science, 2004, 221(1-4), 62-68. DOI: https://doi.org/10.1016/S01694332(03)00753-0 
[20]. Oraon, B., Majumdar, C., Ghosh, B., Improving hardness of electroless Ni-B coatings using optimized deposition conditions and annealing, Materials \& Design, 2008, 29(7), 1412-1418. DOI: https://doi.org/10.1016/j.matdes.2007.09.005

[21]. Ogihara, H., Wang, H., Saji, T., Electrodeposition of Ni-B/SiC composite films with high hardness and wear resistance, Applied Surface Science, 2014, 296(1), 108-113. DOI: https://doi.org/10.1016/j.apsusc.2014.01.057

[22]. Narayanan, T. S. N. S., Krishnaveni, K., Seshadri, S. K. Electroless Ni-P/Ni-B dúplex coatings: preparation and evaluation of microhardness, wear and corrosion resistance, Materials Chemistry and Physics, 2003, 82(3), 771-779. DOI: https://doi.org/10.1016/S02540584(03)00390-0

[23]. Azouani, O., Keddam, M., Brahimi, A., Sehisseh, A., Diffusion kinetics of boron in the X200CrMoV12 high-alloy steel, Journal of Mining Metallurgy, Section B: Metallurgy, 2015, 51(1, B), 49-54. DOI: https://doi.org/10.2298/JMMB140404009A

[24]. Stewart, K., Boronizing protects metals against wear, Advanced Materials and Processes, 1997, 151(2), 23-25.

[25]. Kartal, G., Kahvecioglu, O., Timur, S., Investigating the morphology and corrosion behavior of electrochemically borided steel, Surface and Coatings Technology, 2006, 200(11), 35903593. DOI: https://doi.org/10.1016/j.surfcoat.2005.02.210

[26]. Dearnley, P. A., Bell, T., Engineering the surface with boron based materials, Surface Engineering, 1985, 1(3), 203-217. DOI: https://doi.org/10.1179/sur.1985.1.3.203

[27]. Minkevich, A. N., Diffusion boride layers in metals, Metal Science and Heat Treatment of Metals, 1961, 3(7-8), 347-351. DOI: https://doi.org/10.1007/BF00810400

[28]. Yıldız, İ., Güneş, İ, \%3,0 Mg içeren borlanmış Co-Mg alaşımının yüzey özelliklerinin incelenmesi, El-Cezerî Fen ve Mühendislik Dergisi, 2019, 6(3), 533-542. DOI: https://doi.org/10.31202/ecjse.556680

[29]. Çelik, A. G., Güneş, İ., Borlanmış sementasyon çeliğinin tribolojik özelliklerinin incelenmesi, El-Cezerî Fen ve Mühendislik Dergisi, 2019, 6(2), 333-344. DOI: https://doi.org/10.31202/ecjse.513866

[30]. Bugdayci, M., Alkan, M., Turan, A., Yücel, O., Production of iron based alloys from mill scale through metallothermic reduction, High Temperature Materials and Processes, 2018, 37(9-10), 889-898. DOI: https://doi.org/10.1515/htmp-2017-0073

[31]. Bugdayci, M., Turan, A., Alkan, M., Yucel, O., Effect of reductant type on the metallothermic magnesium production process, High Temperature Materials and Processes, 2018, 37(1), 1-8. DOI: https://doi.org/10.1515/htmp-2016-0197

[32]. Turan, A., Bugdayci, M., Yucel, O., Self-propagating high temperature synthesis of $\mathrm{TiB}_{2}$, 2015, 34(2), 185-193. DOI: https://doi.org/10.1515/htmp-2014-0021

[33]. Benzeşik, K., Turan, A., Yücel, O., Volume combustion synthesis of $\mathrm{Li}_{4} \mathrm{SiO}_{4}, \mathrm{XV}$. International Symposium on Self-propagating High-temperature Synthesis (SHS 2019), 16-20 Eylül 2019, Moskova, Rusya.

[34]. Kaplan, S. S., Sonmez, M. S., Single step solution combustion synthesis of hexagonal $\mathrm{WO}_{3}$ powders as visible light photocatalysts, 2020, 240(1), 122-152. DOI: https://doi.org/10.1016/j.matchemphys.2019.122152 